\title{
Joint Contract under Inequity Aversion
}

\section{Guangxing WEI, Yanhong QIN}

School of Management, Chongqing Jiaotong University, Chongqing, China.

Email:wgx777@126.com

Received March $5^{\text {th }}, 2009$; revised May $7^{\text {th }}, 2009$; accepted June $12^{\text {th }}, 2009$.

\begin{abstract}
The standard contract theory adopts the traditional hypothesis of pure self-interest. However, a series of game experiments have proven that people are not any self-interest but also inequity averse. Then, how will the inequity aversion influence the optimal contract for multiple agents? This paper attempts to obtain new theoretical insights by incorporating inequity aversion into the standard frame of optimal contract design. The optimal contract under relatively weak inequity aversion is found to be the relative joint contract, by which payment to each independent agent increases with his own output and others' and agents with higher output will be paid more, while what under strong, even very strong, inequity aversion is the egalitarian joint contract, by which payment to each independent agent is always equal and hence agents with lower output will not be paid less. Moreover, it is shown that the inequity aversion results in incentive efficiency losses as agents with inequity aversion will suffer disutility in face of unfair allocation. Consequently, the principal has to pay additional inequity rent and risk compensation for inequity aversion to the agents, which both are the incentive efficiency losses resulted from inequity aversion and have never been explored by the standard contract theory, besides information rent and risk compensation for asymmetric information, which both have been probed in the standard contract theory deeply. In this way, this paper designs the optimal contracts for multiple agents with more realistic assumptions and hence can explain real economic behaviors more properly.
\end{abstract}

Keywords: inequity aversion, contract design, optimal contract, principal-agent, contract theory

\section{Introduction}

The hypothesis of pure self-interest has been proved correct in many situations and has been highly useful in designing optimal incentive contracts. It is normal for the standard contract theory to assume that the agent maximizes his profit to the extent of his receipts minus the cost of private effort while the principal maximizes his wealth to the extent of profits generated by agents minus payments made to the agents. However, in recent years, a series of game experiments such as ultimatum game and dictator game [1], trust game [2], gift exchange game [3] and public good game [4], have been proving that not all people are motivated exclusively by pure self-interest considerations, which are reviewed in [5] and [6]. Actually, many people are inequity averse and prefer more fair allocation. Both inequity aversion and self-interest preference affect behaviors, but sometimes their effects are not consistent. For example, people pursuing inequity aversion will sacrifice some of their own material payoffs in order to realize a more fair allocation while people pursuing pure self-interest won't. When the related material payoffs are relatively large, the inequity aver- sion is the dominating factor in deciding individual behavior, while in case of relatively small, the self-interest is the dominating. Some new theoretical models, such as $[7,8,9]$ and [10], have been developed to explain various experimental results by incorporating inequity aversion into the framework of utility maximization.

Then, how will the inequity aversion influence the optimal contract for multiple agents? This paper tries to design the optimal contract for multiple agents with inequity aversion and further examines the influence of inequity aversion on incentive efficiency in the approach of FS Model developed by [7] with the improvement of replacing the assumption of risk neutrality with risk aversion. The optimal contract under inequity aversion is found to be the joint contract by which payment to each independent agent must depend on both his own output and others', instead of the independent contract which is the optimal contract given by standard contract theory and pays each independent agent according to his own output. To be concrete, the optimal contract under relatively weak inequity aversion is the relative joint contract, 
by which payment to each independent agent increases with his own output and others' and agents with higher output will be paid more, while that that under strong, even very strong, inequity aversion is the egalitarian joint contract, by which payment to each independent agent is always equal and hence agents with lower output will not be paid less. Moreover, it is shown that the inequity aversion adds a new incentive constrain and surely results in incentive efficiency losses because agents with inequity aversion will suffer disutility in face of unfair allocation. As a result, the principal has to pay additional inequity rent and risk compensation for inequity aversion to the agents, which both are the incentive efficiency losses resulted from inequity aversion and have never been explored by the standard contract theory, besides information rent and risk compensation for asymmetric information, which both have been investigated deeply in the standard contract theory.

There are some existing related literatures. Two brief but good recent surveys are [11] and [12]. The optimal contract for multiple agents showing jealousy, which is one side of inequity aversion, is analyzed in [13] and [14], while $[15,16,17,18,19]$ and $[20]$ studied the incentive contract when agents exhibit inequity aversion or some other forms of social preferences by restricting the class of contracts to linear schemes. Literature $[15,16]$ focused on the case of a single agent, while $[17,18,19]$ and [20] examined that of multiple agents. Tournament amongst agents with inequity aversion is considered in [21] and [22], while [23,24] and [25] probed the influence of inequity aversion on team incentives. Furthermore, [26,27] and [28] studied peer pressure, a special form of social preference similar to inequity aversion. As the most relevant literature, [29] established the optimal contract for multiple agents showing inequity aversion with assumption of risk neutrality and limited liability constraints, while this paper assumes that agents with inequity aversion are also risk averse and there is no limited liability constraint. Thus, some forms of contracts outlined by [29], are unrealistic, while contracts offered in this paper are all practicable. Furthermore, [29] didn't investigate the influence of inequity aversion on incentive efficiency, while this paper analyzes it and concludes that inequity aversion results in incentive efficiency losses, including inequity rent and risk compensation for inequity aversion.

The remainder of this paper is organized as follows. Section 2 briefly summarizes the theory of inequity aversion. Section 3 presents the basic model and Section 4 provides the solution. Section 5 analyzes the optimal joint contract. Section 6 studies the influence of inequity aversion on incentive efficiency. A numerical example is given in Section 7. Finally, Section 8 draws conclusion.

\section{Theory of Inequity Aversion}

A lot of game experiments and literatures argue that people often care about material payoffs of others, dislike unfair allocation, and reciprocate kind or unkind behaviors of others. Generally speaking, these behaviors are motivated by social preferences. There are two approaches to describe the social preferences: the distributional approach and the motivational approach, which are reviewed in [30]. The distributional approach, such as that of [7] and [8], is concerned only with effects of actions on final allocations. It neglects intentions behind behaviors and solely focuses on final allocations but still fares well in explaining observed experimental results while remaining quite simple and tractable. The motivational approach, such as that of $[9,10,31]$ and [32], pays attention to the intentions behind behaviors and tries to actually model reciprocity, by which any friendly action will be returned and any spiteful action will be retaliated. It is certainly closer to a realistic modeling of human behavior, but is not analytically tractable. As one kind of the distributional approach, the theory of inequity aversion emphasizes preference for fair allocation. When his material payoff is below others', the agent suffers jealous disutility, while when his material payoff is above others', he suffers compassion disutility. The sum of disutility arising from jealousy and compassion is defined as inequity aversion disutility. The theory of inequity aversion, especially the FS Model proposed by [7], is reasonable enough, simple and quite tractable. Therefore, it is widely accepted and applied. In this paper, we also adopt the FS Model, expressed by

$$
\begin{aligned}
u_{i}= & x_{i}-\frac{\alpha_{i}}{n-1} \sum_{j \neq i} \max \left(x_{j}-x_{i}, 0\right) \\
& -\frac{\beta_{i}}{n-1} \sum_{j \neq i} \max \left(x_{i}-x_{j}, 0\right)
\end{aligned}
$$

where $u_{i}$ denotes the utility of $i$ under the assumption of risk neutrality, $x_{i}$ represents the material payoff of $i$ while $x_{j}$ illustrates that of $j, n$ denotes the number of agents in the reference group,

and

$$
\frac{\alpha_{i}}{n-1} \sum_{j \neq i} \max \left(x_{j}-x_{i}, 0\right)
$$

$$
\frac{\beta_{i}}{n-1} \sum_{j \neq i} \max \left(x_{i}-x_{j}, 0\right)
$$

illustrate the jealous disutility and compassion disutility respectively, where $\alpha_{i}$ and $\beta_{i}$ denote the degree of jealousy and that of compassion respectively with the constraint $\alpha_{i}>\beta_{i}$ and $1>\beta_{i} \geq 0$. Here, $\alpha_{i}>\beta_{i}$ im- 
plies that the jealous disutility resulted from disadvantageous inequity is greater than the compassion disutility originated from advantageous inequity, while $1>\beta_{i} \geq 0$ implies that although the agent with inequity aversion suffers compassion disutility, he still prefers more. Particularly, $\alpha_{i}=\beta_{i}=0$ denotes pure self-interest.

Although the FS Model solely focuses on the final allocation and ignores the behavioral intentions, it can explain almost all the experimental results and capture many reciprocal behaviors. Therefore, it is widely applied. However, it is based on the assumption of risk neutrality and, thus, is not practicable to some extent. For example, we usually feel more jealous when receiving a payment of 600 dollars while our colleagues receive 700 than when receiving 6000 while our colleagues receive 6100. But the FS Model supposes that we feel the same degree of jealousy and hereby suffer the same jealous disutility in the above two cases, which is obviously not in accordance with normal feelings. Consequently, in this paper, we improve the FS Model and suppose that in order to judge whether the allocation is fair or not, each agent compares the utility derived from his payment with others' in the reference group one by one, instead of directly comparing the payment, which is the assumption of the FS Model. In this way, the revised FS Model, which is based on risk aversion, can be denoted as

$$
\begin{aligned}
U_{i}= & u_{i}\left(x_{i}\right)-\frac{\alpha_{i}}{n-1} \sum_{j \neq i} \max \left[u_{j}\left(x_{j}\right)-u_{i}\left(x_{i}\right), 0\right] \\
& -\frac{\beta_{i}}{n-1} \sum_{j \neq i} \max \left[u_{i}\left(x_{i}\right)-u_{j}\left(x_{j}\right), 0\right]
\end{aligned}
$$

where $u_{i}\left(x_{i}\right)$ represents the utility of $i$, derived from his payment $x_{i}$, and $u_{j}\left(x_{j}\right)$ illustrates the utility of $j$, derived from his payment $x_{j}$.

It is clear that the revised FS model is more practicable than the FS Model because the agent surely suffers more jealous disutility when he receives a payment of 600 dollars while his colleagues receive 700 than when he receives 6000 while his colleagues receive 6100, which is in accordance with normal feelings. Furthermore, the revised model is more general than the FS Model. In fact, the FS Model is a special case of the revised model.

\section{The Basic Model}

The following models the interaction between a risk neutral, pure self-interest, profit maximizing principal and two symmetric risk averse, utility maximizing agents $\mathrm{A}$ and $\mathrm{B}$, who are inequity averse towards each other and engage in Task 1 and Task 2 separately. The degrees of jealousy and compassion are denoted as $\alpha$ and $\beta$ respectively, subject to $\alpha>\beta$ and $1>\beta \geq 0$. Each agent can choose an effort from the set $e=\left\{e_{L}, e_{H}\right\}$ to exert, where low effort $e_{L}$ costs 0 while high effort $e_{H}$ costs $c$. When effort $e_{i}$ is made, the task generates high output $x^{h}$ with probability $p_{i}$, and low output $x^{h}$ with probability $1-p_{i}$, which follow the constraint $0<p_{L}<p_{H}<1$. The reservation utility of each agent is supposed to be zero. The timing of the game is as follows. First, the principal offers a contract to the agents. Second, the agents decide whether to accept or reject the contract. If the contract is rejected, the game ends and each agent receives zero, the reservation utility. Third, after accepting the contract, the agents exert efforts simultaneously. Finally, the outputs of the tasks are realized and the transfers are made.

The contract is represented by $W=\left(w_{h h}, w_{h l}, w_{l h}, w_{l l}\right)$, in which $w_{a b}(a, b=h, l)$ denotes the payment to $i(=$ $A, B)$ and $w_{b a}$ denotes the payment to $j \neq i$ by the contract, when the output of $i$ is $x^{a}$ and the output of $j$ is $x^{b}$. If $w_{a h}=w_{a l}$, it is an independent contract, by which the payment to each agent depends on only his own output. On the contrary, if $w_{a h} \neq w_{a l}$, it is a joint contract, by which the payment to each agent depends on both his own output and others' output.

Therefore, by (2), the utility of each agent can be denoted as

$$
\begin{aligned}
U= & u\left(w_{a b}\right)-\alpha \max \left[u\left(w_{b a}\right)-u\left(w_{a b}\right), 0\right] \\
& -\beta \max \left[u\left(w_{a b}\right)-u\left(w_{b a}\right), 0\right]-c(e)
\end{aligned}
$$

where $u(\cdot)$ meets the conditions $u^{\prime}>0, u^{\prime \prime}<0$ and $u(0)=0, u\left(w_{a b}\right)$ represents the utility of one agent (A or B) derived from his payment, $u\left(w_{b a}\right)$ illustrates that of the other agent, and $\alpha \max \left[u\left(w_{b a}\right)-u\left(w_{a b}\right), 0\right]$ denotes the jealous disutility, $\beta \max \left[u\left(w_{a b}\right)-u\left(w_{b a}\right), 0\right]$ is the compassion disutility, $c(e)$ is the cost of effort and $c\left(e_{L}\right)=0$ and $c\left(e_{H}\right)=c$.

If both $\mathrm{A}$ and $\mathrm{B}$ make high effort, the expected utility of each agent, derived from the payment, is

$$
\begin{aligned}
E U^{W}\left(e_{H} \mid e_{H}\right)= & p_{H}^{2} u\left(w_{h h}\right)+p_{H}\left(1-p_{H}\right)\left[u\left(w_{h l}\right)\right. \\
& \left.+u\left(w_{l h}\right)\right]+\left(1-p_{H}\right)^{2} u\left(w_{l l}\right)
\end{aligned}
$$

And the expected inequity aversion disutility of each agent can be represented by

$$
E U^{F}\left(e_{H} \mid e_{H}\right)=\left\{\begin{array}{c}
p_{H}\left(1-p_{H}\right)(\alpha+\beta) \\
{\left[u\left(w_{h l}\right)-u\left(w_{l h}\right)\right], w_{h l} \geq w_{l h}} \\
p_{H}\left(1-p_{H}\right)(\alpha+\beta) \\
{\left[u\left(w_{l h}\right)-u\left(w_{h l}\right)\right], w_{h l}<w_{l h}}
\end{array}\right.
$$

So, the expected utility of each agent can be denoted as 


$$
E U\left(e_{H} \mid e_{H}\right)=E U^{W}\left(e_{H} \mid e_{H}\right)-E U^{F}\left(e_{H} \mid e_{H}\right)-c
$$

where $E U^{W}\left(e_{H} \mid e_{H}\right)$ illustrates the expected utility derived from the payment, $E U^{F}\left(e_{H} \mid e_{H}\right)$ is the expected inequity aversion disutility and $c$ is the cost of high effort $e_{H}$.

On the other hand, if $i(=A, B)$ makes low effort $e_{L}$ while $j \neq i$ makes high effort $e_{H}$, the expected utility of $i$, derived from the payment, is illustrated as

$$
\begin{aligned}
E U^{W}\left(e_{L} \mid e_{H}\right)= & p_{L} p_{H} u\left(w_{h h}\right) \\
& +p_{L}\left(1-p_{H}\right) u\left(w_{h l}\right) \\
& +\left(1-p_{L}\right) p_{H} u\left(w_{l h}\right) \\
& +\left(1-p_{L}\right)\left(1-p_{H}\right) u\left(w_{l l}\right)
\end{aligned}
$$

And the expected inequity aversion disutility of $i$ can be represented by

$$
E U^{F}\left(e_{L} \mid e_{H}\right)=\left\{\begin{array}{c}
p_{L}\left(1-p_{H}\right) \beta\left[u\left(w_{h l}\right)-u\left(w_{l h}\right)\right] \\
+\left(1-p_{L}\right) p_{H} \alpha\left[u\left(w_{h l}\right)\right. \\
\left.-u\left(w_{l h}\right)\right], w_{h l} \geq w_{l h} \\
p_{L}\left(1-p_{H}\right) \alpha\left[u\left(w_{l h}\right)-u\left(w_{h l}\right)\right] \\
+\left(1-p_{L}\right) p_{H} \beta\left[u\left(w_{l h}\right)\right. \\
\left.-u\left(w_{h l}\right)\right], w_{h l}<w_{l h}
\end{array}\right.
$$

So, the expected utility of the agent who makes low effort $e_{L}$ while the other makes high effort $e_{H}$ can be denoted as

$$
E U\left(e_{L} \mid e_{H}\right)=E U^{W}\left(e_{L} \mid e_{H}\right)-E U^{F}\left(e_{L} \mid e_{H}\right)
$$

where $E U^{W}\left(e_{L} \mid e_{H}\right)$ is the expected utility derived from the payment and $E U^{F}\left(e_{L} \mid e_{H}\right)$ is the expected inequity aversion disutility.

The principal designs the optimal contract subject to the participation constraint and the incentive compatibility constraint to maximize the expected profit, which is illustrated as

\section{[P1]}

$$
\begin{gathered}
\min _{w_{h h}, w_{h l}, w_{l h}, w_{l l}} p_{H}^{2} w_{h h}+p_{H}\left(1-p_{H}\right)\left(w_{h l}+w_{l h}\right)+\left(1-p_{H}\right)^{2} w_{l l} \\
\text { st. }\left\{\begin{array}{l}
(P C) E U\left(e_{H} \mid e_{H}\right) \geq 0 \\
(I C) E U\left(e_{H} \mid e_{H}\right) \geq E U\left(e_{L} \mid e_{H}\right)
\end{array}\right.
\end{gathered}
$$

where $P C$ denotes the participation constraint and IC illustrates the incentive compatibility constraint. The next section solves [P1], and hereby derives the optimal contract for multiple agents with inequity aversion.

\section{Solutions to the Model}

In order to solve [P1], and obtain the optimal contract, the following lemma is necessary, where a contract is feasible if it satisfies the participation constraint and the incentive compatibility constraint.

LEMMA: For every feasible contract $W^{+}$with $w_{h l}^{+} \leq w_{l h}^{+}$, there exist a feasible contract $W$ with $w_{h l} \geq w_{l h}$ where the expected payment to each agent by contract $W$ equals that by contract $W^{+}$.

Proof of Lemma: Contract $W^{+}$is feasible and hereby satisfies both the participation constraint and the incentive compatibility constraint. From (4), (5), (6), PC and $w_{h l}^{+} \leq w_{l h}^{+}$, the participation constraint for contract $W^{+}$can be denoted as

$$
\begin{aligned}
& p_{H}^{2} u\left(w_{h h}^{+}\right)+p_{H}\left(1-p_{H}\right)\left[u\left(w_{h l}^{+}\right)+u\left(w_{l h}^{+}\right)\right] \\
& \quad+\left(1-p_{H}\right)^{2} u\left(w_{l l}^{+}\right) \\
& \quad-p_{H}\left(1-p_{H}\right)(\alpha+\beta)\left[u\left(w_{l h}^{+}\right)-u\left(w_{h l}^{+}\right)\right] \geq c
\end{aligned}
$$

From (4), (5), (6), (7), (8), (9), IC and $w_{h l}^{+} \leq w_{l h}^{+}$, the incentive compatibility constraint for contract $W^{+}$can be represented by

$$
\begin{aligned}
& p_{H}\left[u\left(w_{h h}^{+}\right)-u\left(w_{l h}^{+}\right)\right] \\
& \left.+\left(1-p_{H}\right)\left[u\left(w_{h l}^{+}\right)-\right) u\left(w_{l l}^{+}\right)\right] \\
& +\left[\beta p_{H}-\alpha\left(1-p_{H}\right)\right]\left[u\left(w_{l h}^{+}\right)-u\left(w_{h l}^{+}\right)\right] \\
& \quad \geq \frac{c}{p_{H}-p_{L}}
\end{aligned}
$$
is

The expected payment to each agent by contract $W^{+}$

$$
\begin{aligned}
E W^{+}= & p_{H}^{2} w_{h h}^{+}+p_{H}\left(1-p_{H}\right)\left(w_{h l}^{+}+w_{l h}^{+}\right) \\
& +\left(1-p_{H}\right)^{2} w_{l l}^{+}
\end{aligned}
$$

Contract $W$ is defined by $w_{h h}=w_{h h}^{+}, w_{l l}=w_{l l}^{+}$, $w_{h l}=w_{l h}^{+}$and $w_{l h}=w_{h l}^{+}$. Obviously, it satisfies $w_{h l} \geq w_{l h}$, and the expected payment to each agent by contract $W$ equals that by contract $W^{+}$. Therefore, if contract $W$ is feasible, the lemma is proved. From (4), (5), (6), $P C$ and $w_{h l} \geq w_{l h}$, the participation constraint for contract $W$ is

$$
\begin{aligned}
& p_{H}^{2} u\left(w_{h h}\right)+p_{H}\left(1-p_{H}\right)\left[u\left(w_{h l}\right)+u\left(w_{l h}\right)\right] \\
& \quad+\left(1-p_{H}\right)^{2} u\left(w_{l l}\right) \\
& \quad-p_{H}\left(1-p_{H}\right)(\alpha+\beta)\left[u\left(w_{h l}\right)-u\left(w_{l h}\right)\right] \geq c
\end{aligned}
$$

According to the definition of contract $W$ and (10), it is clear that (13) holds. Thus, contract $W$ satisfies the participation constraint. And from (4), (5), (6), (7), (8), (9), IC and $w_{h l} \geq w_{l h}$, the incentive compatibility constraint for contract $W$ can be denoted as 


$$
\begin{aligned}
p_{H} & {\left[u\left(w_{h h}\right)-u\left(w_{l h}\right)\right] } \\
+ & \left(1-p_{H}\right)\left[u\left(w_{h l}\right)-u\left(w_{l l}\right)\right] \\
+ & {\left[\alpha p_{H}-\beta\left(1-p_{H}\right)\right]\left[u\left(w_{h l}\right)-u\left(w_{l h}\right)\right] } \\
& \geq \frac{c}{p_{H}-p_{L}}
\end{aligned}
$$

which by the definition of contract $W$ is equivalent to

$$
\begin{aligned}
p_{H} & {\left[u\left(w_{h h}^{+}\right)-u\left(w_{h l}^{+}\right)\right] } \\
+ & \left(1-p_{H}\right)\left[u\left(w_{l h}^{+}\right)-u\left(w_{l l}^{+}\right)\right] \\
+ & {\left[\alpha p_{H}-\beta\left(1-p_{H}\right)\right]\left[u\left(w_{l h}^{+}\right)-u\left(w_{h l}^{+}\right)\right] } \\
& \geq \frac{c}{p_{H}-p_{L}}
\end{aligned}
$$

Subtracting the left-hand side of (11) from the left-hand side of (15),

$$
\begin{gathered}
u\left(w_{l h}^{+}\right)-u\left(w_{h l}^{+}\right)+(\alpha-\beta)\left[u\left(w_{l h}^{+}\right)-u\left(w_{h l}^{+}\right)\right] \\
=(1+\alpha-\beta)\left[u\left(w_{l h}^{+}\right)-u\left(w_{h l}^{+}\right)\right] \geq 0
\end{gathered}
$$

where $\quad \alpha>\beta$ and $u\left(w_{l h}^{+}\right)-u\left(w_{h l}^{+}\right) \geq 0 \quad$ because $w_{h l}^{+} \leq w_{l h}^{+}$and $u^{\prime}>0$. The right-hand side of (11) is the same as the right-hand side of (15). Then, (14) holds. Therefore, contract $W$ satisfies the incentive compatibility constraint also and hereby is feasible.

\section{Q.E.D.}

By the above lemma, the optimal contract satisfies $w_{h l} \geq w_{l h}$. Then, [P1] can be simplified as

[P2]

$$
\begin{aligned}
& \min _{w_{h h}, w_{h l}, w_{l h}, w_{l l}} p_{H}^{2} w_{h h}+p_{H}\left(1-p_{H}\right)\left(w_{h l}+w_{l h}\right)+\left(1-p_{H}\right)^{2} w_{l l} \\
& \text { st. }\left\{\begin{array}{c}
(P C) p_{H}^{2} u\left(w_{h h}\right) \\
+p_{H}\left(1-p_{H}\right)\left[u\left(w_{h l}\right)+u\left(w_{l h}\right)\right] \\
+\left(1-p_{H}\right)^{2} u\left(w_{l l}\right) \\
-p_{H}\left(1-p_{H}\right)(\alpha+\beta)\left[u\left(w_{h l}\right)-u\left(w_{l h}\right)\right] \geq c \\
(I C) p_{H}\left[u\left(w_{h h}\right)-u\left(w_{l h}\right)\right] \\
+\left(1-p_{H}\right)\left[u\left(w_{h l}\right)-u\left(w_{l l}\right)\right] \\
+\left[\alpha p_{H}-\beta\left(1-p_{H}\right)\right]\left[u\left(w_{h l}\right)-u\left(w_{l h}\right)\right] \geq \frac{c}{p_{H}-p_{L}}
\end{array}\right.
\end{aligned}
$$

In order to solve [P2], denote $f(\cdot)=u^{-1}(\cdot)$, which satisfies $f^{\prime}>0, f^{\prime \prime}>0$ and $f(0)=0$ because $u^{\prime}>0$, $u^{\prime \prime}<0$ and $u(0)=0$. Then, let $u\left(w_{a b}\right)=u_{a b}$, [P2] is simplified as

[P3]

$$
\begin{gathered}
\min _{u_{h h}, u_{h l}, u_{l h}, u_{l l}} p_{H}^{2} f\left(u_{h h}\right)+p_{H}\left(1-p_{H}\right)\left[f\left(u_{h l}\right)+f\left(u_{l h}\right)\right] \\
+\left(1-p_{H}\right)^{2} f\left(u_{l l}\right)
\end{gathered}
$$

$$
\text { st. }\left\{\begin{array}{l}
(P C) p_{H}^{2} u_{h h}+p_{H}\left(1-p_{H}\right)\left(u_{h l}+u_{l h}\right) \\
\quad+\left(1-p_{H}\right)^{2} u_{l l}-p_{H}\left(1-p_{H}\right)(\alpha+\beta)\left(u_{h l}-u_{l h}\right) \geq c \\
(I C) p_{H} u_{h h}+\left(1-p_{H}\right) u_{h l}-p_{H} u_{l h}-\left(1-p_{H}\right) u_{l l} \\
\quad+\left[\alpha p_{H}-\beta\left(1-p_{H}\right)\right]\left(u_{h l}-u_{l h}\right) \geq \frac{C}{p_{H}-p_{L}}
\end{array}\right.
$$

which is a standard problem of convex programming. It is easy to achieve the solution

$$
\left\{\begin{array}{l}
f^{\prime}\left(u_{h h}^{*}\right)=\frac{\lambda p_{H}+\mu}{p_{H}} \\
f^{\prime}\left(u_{h l}^{*}\right)=\frac{\lambda p_{H}+\mu}{p_{H}}-y(\alpha, \beta) \\
f^{\prime}\left(u_{l h}^{*}\right)=\frac{\lambda\left(1-p_{H}\right)-\mu}{1-p_{H}}+y(\alpha, \beta) \\
f^{\prime}\left(u_{l l}^{*}\right)=\frac{\lambda\left(1-p_{H}\right)-\mu}{1-p_{H}}
\end{array}\right.
$$

where $\lambda$ is the Lagrangian multiplier of $P C, \mu$ is that of $I C$, and

$$
y(\alpha, \beta)=\frac{\alpha p_{H}\left[\lambda\left(1-p_{H}\right)-\mu\right]+\beta\left(\lambda p_{H}+\mu\right)\left(1-p_{H}\right)}{p_{H}\left(1-p_{H}\right)}
$$

Furthermore, denote $k(\cdot)$ as the inverse function of $f^{\prime}(\cdot)$. Here, $k^{\prime}>0$ because $f^{\prime \prime}>0$. Then, the above (17) equals

$$
\left\{\begin{array}{l}
u_{h h}^{*}=k\left[\frac{\lambda p_{H}+\mu}{p_{H}}\right] \\
u_{h l}^{*}=k\left[\frac{\lambda p_{H}+\mu}{p_{H}}-y(\alpha, \beta)\right] \\
u_{l h}^{*}=k\left[\frac{\lambda\left(1-p_{H}\right)-\mu}{1-p_{H}}+y(\alpha, \beta)\right] \\
u_{l l}^{*}=k\left[\frac{\lambda\left(1-p_{H}\right)-\mu}{1-p_{H}}\right]
\end{array}\right.
$$

Consequently, the solution to [P1], or the optimal contract for independent agents $\mathrm{A}$ and $\mathrm{B}$ with inequity aversion, $W^{*}=\left(f\left(u_{h h}^{*}\right), f\left(u_{h l}^{*}\right), f\left(u_{l h}^{*}\right), f\left(u_{l l}^{*}\right)\right)$, is defined by (18) and (19).

\section{The Joint Contracts}

In case of $\alpha=\beta=0$, by (18), $y(0,0)=0$. Furthermore, from (19), $u_{h h}^{*}=u_{h l}^{*}$ and $u_{l h}^{*}=u_{l l}^{*}$, by which the optimal contract for multiple independent pure self-interest agents is the independent contract and the payment to each agent depends on only his own output. This is the sufficient statistics result revealed by [33] and [34] in the standard contract theory. 
In case of $\alpha>\beta>0$, by (17), (18) and $f^{\prime}>0$,

$$
\left\{\begin{array}{l}
\frac{\partial y}{\partial \alpha}=\frac{\lambda\left(1-p_{H}\right)-\mu}{1-p_{H}}=f^{\prime}\left(u_{l l}^{*}\right)>0 \\
\frac{\partial y}{\partial \beta}=\frac{\lambda p_{H}+\mu}{p_{H}}=f^{\prime}\left(u_{h h}^{*}\right)>0
\end{array}\right.
$$

From (20) and $\alpha>\beta>0, y(\alpha, \beta)>0$. Then, by $y(\alpha, \beta)>0, \quad k^{\prime}>0$ and (19), $u_{h h}^{*}>u_{h l}^{*}$ and $u_{l h}^{*}>u_{l l}^{*}$. Moreover, $u_{h l}^{*} \geq u_{l h}^{*}$ definitely holds by the above lemma. Thus, if $\alpha>\beta>0$, the optimal contract surely satisfies $u_{h h}^{*}>u_{h l}^{*} \geq u_{l h}^{*}>u_{l l}^{*}$, by which the optimal contract for multiple independent agents with inequity aversion is the joint contract, and the payment to each agent depends on, and further increases with, both his own output and others' output. Therefore, the sufficient statistics result of the standard contract theory does not work in the optimal contract for agents with inequity aversion. The result that the payment to an independent agent should depend on both his own output and others' is not novel. It appears in the rank order tournament [35] and the rank-order contract [36]. But what this paper exploring is the optimal contract for multiple risk averse agents with inequity aversion, while as pointed out by [33], the rank order tournament is not the optimal contract even for multiple risk averse agents with pure self-interest.

From (18), (19) and (20), it is easy to find that if inequity aversion is strong enough to satisfy

$$
y(\alpha, \beta)=\frac{1}{2}\left[\frac{\lambda p_{H}+\mu}{p_{H}}-\frac{\lambda\left(1-p_{H}\right)-\mu}{1-p_{H}}\right]
$$

there must be $u_{h l}^{*}=u_{l h}^{*}$. And by the above lemma, $u_{h l}^{*} \geq u_{l h}^{*}$ always holds. So, for the inequity aversion stronger than that defined by (21), $u_{h l}^{*}=u_{l h}^{*}$. The joint contract satisfying $u_{h h}^{*}>u_{h l}^{*}=u_{l h}^{*}>u_{l l}^{*}$ is defined as egalitarian joint contract $W^{E}$, by which the payment to each independent agent is always equal, no matter what output each agent achieves. On the other hand, when inequity aversion is weaker than that defined by (21), we can obtain $u_{h l}^{*}>u_{l h}^{*}$ from (18), (19) and (20). The joint contract that satisfies $u_{h h}^{*}>u_{h l}^{*}>u_{l h}^{*}>u_{l l}^{*}$ is defined as relative joint contract $W^{R}$, by which the payment to each independent agent should rest with, and further increase with, both his own output and others' output. Integrating the above two aspects, the following proposition can be obtained.

Proposition 1: The optimal contract under relatively weak inequity aversion is the relative joint contract, while that under strong, even very strong inequity aversion is the egalitarian joint contract.
The relative joint contract is denoted as, $W^{R^{*}}=(f($ $\left.\left.u_{h h}^{*}\right), f\left(u_{h l}^{*}\right), f\left(u_{l h}^{*}\right), f\left(u_{l l}^{*}\right)\right)$ which is defined by (18) and (19). And the egalitarian joint contract can be represented by $W^{E^{* *}}=\left(f\left(u_{h h}^{* *}\right), f\left(u_{m}^{* *}\right), f\left(u_{l l}^{* *}\right)\right)$, which is the solution to the following [P4]. When the intensity of inequity aversion equals, or bigger than that defined by (21), from (18), (19) and (20), $w_{h l}=w_{l h}=w_{m}$ and $u_{h l}=u_{l h}=u_{m}$. Thus, [P3] is simplified as

[P4]

$$
\begin{aligned}
& \min _{u_{h h}, u_{m}, u_{l l}} p_{H}^{2} f\left(u_{h h}\right) \\
& +2 p_{H}\left(1-p_{H}\right) f\left(u_{m}\right)+\left(1-p_{H}\right)^{2} f\left(u_{l l}\right) \\
& \text { st. }\left\{\begin{array}{c}
(P C) p_{H}^{2} u_{h h}+2 p_{H}\left(1-p_{H}\right) u_{m} \\
+\left(1-p_{H}\right)^{2} u_{l l} \geq c \\
(I C) p_{H} u_{h h}+\left(1-2 p_{H}\right) u_{m} \\
-\left(1-p_{H}\right) u_{l l} \geq \frac{c}{p_{H}-p_{L}}
\end{array}\right.
\end{aligned}
$$

The solution can be represented by

$$
\left\{\begin{array}{l}
u_{h h}^{* *}=k\left(\frac{\lambda^{\prime} p_{H}+\mu^{\prime}}{p_{H}}\right) \\
u_{m}^{* * *}=k\left[\frac{2 \lambda^{\prime} p_{H}\left(1-p_{H}\right)+\mu^{\prime}\left(1-2 p_{H}\right)}{2 p_{H}\left(1-p_{H}\right)}\right] \\
u_{l l}^{* *}=k\left[\frac{\lambda^{\prime}\left(1-p_{H}\right)-\mu^{\prime}}{1-p_{H}}\right]
\end{array}\right.
$$

where $\lambda^{\prime}$ is the Lagrangian multiplier of $P C$ while $\mu^{\prime}$ is that of IC.

Obviously, different from the relative joint contract, the egalitarian joint contract is not correlative to the intensity of inequity aversion, although it is the optimal contract under inequity aversion stronger than that of (21).

\section{Incentive Efficiency Losses}

In order to analyze the incentive efficiency losses resulting from inequity aversion clearly, the agency cost of joint contract, which is the optimal contract under inequity aversion is compared with that of independent contract, which is the optimal contract under pure self-interest. If the agency cost of joint contract is higher, the difference is the incentive efficiency losses resulting from inequity aversion. On the contrary, if the agency cost of joint contract is lower, the difference is the incentive efficiency gains stemmed from inequity aversion. This is an easy way to measure the influence of inequity aver- 
sion on incentive efficiency.

\subsection{Case of Relative Joint Contract}

From (19), the payment to each agent by the relative joint contract is

$$
\begin{aligned}
E W_{r}^{*}= & p_{H}^{2} f\left(u_{h h}^{*}\right)+p_{H}\left(1-p_{H}\right) f\left(u_{h l}^{*}\right) \\
& +p_{H}\left(1-p_{H}\right) f\left(u_{l h}^{*}\right)+\left(1-p_{H}\right)^{2} f\left(u_{l l}^{*}\right)
\end{aligned}
$$

And from (3) and (19), the utility of each agent, excluding cost of effort, in every case, is

$$
U_{a b}^{*}=\left\{\begin{array}{l}
U_{h h}^{*}=u_{h h}^{*} \\
U_{h l}^{*}=u_{h l}^{*}-\beta\left(u_{h l}^{*}-u_{l h}^{*}\right) \\
U_{l h}^{*}=u_{l h}^{*}-\alpha\left(u_{h l}^{*}-u_{l h}^{*}\right) \\
U_{l l}^{*}=u_{l l}^{*}
\end{array}\right.
$$

where when each agent achieves the same output, each agent only obtains the utility derived from the payment, while when the output of each agent is unequal, that is, one agent such as A achieves high output while B achieves low output, A suffers additional compassion disutility and B suffers additional jealous disutility, excepting the utility derived from the payment.

On one hand, in order to endow the pure self-interest agent with the same utility as $U_{a b}^{*}$ of (24) in every case, the expected payment that the principal has to make is

$$
\begin{aligned}
E W_{n}^{*}= & p_{H}^{2} f\left(u_{h h}^{*}\right)+p_{H}\left(1-p_{H}\right)\left[f\left(u_{h l}^{*}-\beta\left(u_{h l}^{*}-u_{l h}^{*}\right)\right)\right. \\
& \left.+f\left(u_{l h}^{*}-\alpha\left(u_{h l}^{*}-u_{l h}^{*}\right)\right)\right]+\left(1-p_{H}\right)^{2} f\left(u_{l l}^{*}\right)
\end{aligned}
$$

From (23), (25) and $u_{h l}^{*}>u_{l h}^{*}$, it is clear that the principal has to make higher expected payment to the agent with inequity aversion than that to the pure self-interest agent in order to endow them with the same utility in every case. The extra payment, defined as inequity rent, is caused by inequity aversion and is the compensation for the inequity disutility resulting from unfair allocation. From (23) and (25), the inequity rent can be represented by

$$
\Delta W^{F R^{*}}=E W_{r}^{*}-E W_{n}^{*}
$$

On the other hand, in order to endow the pure self-interest agent with the same utility as $U_{a b}^{*}$ of (24) in every case by the independent contract, the optimal contract for pure self-interest agent offered by the standard contract theory, the expected payment the principal has to make is

$$
\begin{aligned}
E W_{s}^{*}= & p_{H} f\left[p_{H} u_{h h}^{*}+\left(1-p_{H}\right)\left(u_{h l}^{*}-\beta\left(u_{h l}^{*}-u_{l h}^{*}\right)\right)\right] \\
& +\left(1-p_{H}\right) f\left[p_{H}\left(u_{l h}^{*}-\alpha\left(u_{h l}^{*}-u_{l h}^{*}\right)\right)+\left(1-p_{H}\right) u_{l l}^{*}\right]
\end{aligned}
$$

From (25), (27) and Jensen Inequality, $E W_{s}^{*}<E W_{n}^{*}$ because $f^{\prime}>0, f^{\prime \prime}<0$ and $u_{h l}^{*}>u_{l h}^{*}$, by which the relative joint contract, the optimal contract under inequity aversion, requires the principal to make more payment than that the independent contract, the optimal contract under pure self-interest, requires, because the payment to each agent depends not only on his own output but also on others' by the relative joint contract and hereby, each agent is confronted with higher risk. The extra payment required by the relative joint contract, i.e. more than that the independent contract requires, is the compensation for the additional higher risk, which is defined as the risk compensation for inequity aversion. From (25) and (27), it can be denoted as

$$
\Delta W^{F L^{*}}=E W_{n}^{*}-E W_{s}^{*}
$$

Both the inequity rent and the risk compensation for inequity aversion are incentive efficiency losses resulting from inequity aversion. The sum, defined as inequity aversion losses, are additional compensations to agents with inequity aversion more than those to pure self-interest agents, by (26) and (28), can be denoted as

$$
\Delta W^{F C^{*}}=\Delta W^{F R^{*}}+\Delta W^{F L^{*}}=E W_{r}^{*}-E W_{s}^{*}
$$

$$
\text { From } u_{h l}^{*}>u_{l h}^{*} \text { and } f^{\prime}>0 \text {, }
$$

$$
\frac{\partial \Delta W^{F C^{*}}}{\partial \alpha}>0 \text { and } \frac{\partial \Delta W^{F C^{*}}}{\partial \beta}>0,
$$

by which inequity aversion losses increase with the intensity of inequity aversion. Therefore, the more inequity averse the agents are, the more additional compensations, including the inequity rent and the risk compensation for inequity aversion, the principal has to pay. Formally, the following conclusion can be drawn.

Proposition 2: By the relative joint contract, the principal has to pay the inequity rent and risk compensation for inequity aversion, which both are the incentive efficiency losses resulting from inequity aversion, and increase with the intensity of inequity aversion.

Inequity rent is the compensation for inequity disutility resulting from unfair allocation of material payoff, and the risk compensation for inequity aversion is the compensation for the extra risk, i.e. risk increased by the relative joint contract.

From (24), the expected utility of each agent, excluding cost of effort, is illustrated as

$$
\begin{aligned}
E U^{*}= & p_{H}^{2} u_{h h}^{*}+p_{H}\left(1-p_{H}\right)\left[u_{h l}^{*}\right. \\
& \left.+u_{l h}^{*}-(\alpha+\beta)\left(u_{h l}^{*}-u_{l h}^{*}\right)\right]+\left(1-p_{H}\right)^{2} u_{l l}^{*}
\end{aligned}
$$

If the principal knows the efforts of the agents, he only has to pay a certain amount, as given by 


$$
\begin{aligned}
W^{C E^{*}}= & f\left(E U^{*}\right) \\
= & f\left(p_{H}^{2} u_{h h}^{*}+p_{H}\left(1-p_{H}\right)\left(u_{h l}^{*}+u_{l h}^{*}-(\alpha+\beta)\right.\right. \\
& \left.\left.\left(u_{h l}^{*}-u_{l h}^{*}\right)\right)+\left(1-p_{H}\right)^{2} u_{l l}^{*}\right)
\end{aligned}
$$

Then, from (27) and (31), the risk compensation for asymmetric information is denoted as

$$
\Delta W^{R C^{*}}=E W_{s}^{*}-W^{C E^{*}}
$$

which is the so-called risk compensation discussed in the standard contract theory.

The agency cost by the relative joint contract is the sum of the above inequity rent, risk compensation for inequity aversion and risk compensation for asymmetric information. So,

$$
A C^{*}=\Delta W^{F R^{*}}+\Delta W^{F L^{*}}+\Delta W^{R C^{*}}
$$

Comparatively, the agency cost for pure self-interest agents includes only the risk compensation for asymmetric information. Both the inequity rent and the risk compensation for inequity aversion are incentive efficiency losses arising from inequity aversion. According to Proposition 2, the more intense inequity aversion, the higher would be the incentive efficiency losses. But, the incentive efficiency losses don't increase infinitely with the inequity aversion because when inequity aversion is strong enough, by Proposition 1, the optimal contract is not yet the relative joint contract, but the egalitarian joint contract, by which the agency cost does not increase with the inequity aversion and hence it is fixed and limited, which is proved in the following subsection.

\subsection{Case of Egalitarian Joint Contract}

From (22), payment to each agent by the egalitarian joint contract is

$$
\begin{aligned}
E W_{r}^{* *}= & p_{H}^{2} f\left(u_{h h}^{* *}\right) \\
& +2 p_{H}\left(1-p_{H}\right) f\left(u_{m}^{* *}\right)+\left(1-p_{H}\right)^{2} f\left(u_{l l}^{* *}\right)
\end{aligned}
$$

From (3) and (22), the utility in every case, excluding the cost of effort, of each agent, is

$$
U_{a b}^{* *}=\left\{\begin{array}{l}
U_{h h}^{* *}=u_{h h}^{* *} \\
U_{m}^{* *}=u_{m}^{* *} \\
U_{l l}^{* *}=u_{l l}^{* *}
\end{array}\right.
$$

It is clear that payment to each agent is always equal by the egalitarian joint contract and, therefore, even agents with inequity aversion don't suffer any inequity disutility.

Furthermore, similar to the former subsection, it is easy to conclude that the risk compensation for inequity aversion by the egalitarian joint contract can be denoted as

$$
\begin{aligned}
\Delta W^{F L^{* *}}= & E W_{r}^{* *}-\left(p_{H} f\left(p_{H} u_{h h}^{* *}+\left(1-p_{H}\right) u_{m}^{* *}\right)\right. \\
& \left.+\left(1-p_{H}\right) f\left(p_{H} u_{m}^{* *}+\left(1-p_{H}\right) u_{l l}^{* *}\right)\right)
\end{aligned}
$$

From (22), (34) and (36), the risk compensation for inequity aversion that each agent receives by the egalitarian joint contract, is fixed and doesn't change with the intensity of inequity aversion. Thus,

Proposition 3: By the egalitarian joint contract, the principal need not pay the inequity rent, and only pay the fixed and hereby limited risk compensation for inequity aversion, which is the incentive efficiency loss resulting from inequity aversion.

From (35), the expected utility of each agent, excluding cost of effort, is represented by

$$
\begin{aligned}
E U^{* *}= & p_{H}^{2} u_{h h}^{* *}+2 p_{H}\left(1-p_{H}\right) u_{m}^{* *} \\
& +\left(1-p_{H}\right)^{2} u_{l l}^{* *}
\end{aligned}
$$

If the principal knows the efforts of all agents, he only has to pay a certain amount as

$$
\begin{aligned}
W^{C E^{* *}}=f\left(E U^{* *}\right)= & f\left(p_{H}^{2} u_{h h}^{* *}+2 p_{H}\left(1-p_{H}\right) u_{m}^{* *}\right. \\
& \left.+\left(1-p_{H}\right)^{2} u_{l l}^{* *}\right)
\end{aligned}
$$

Then, from (34) and (38), the risk compensation for asymmetric information can be derived as

$$
\Delta W^{R C^{* *}}=E W_{r}^{* *}-W^{C E^{* *}}
$$

The agency cost by the egalitarian joint contract equals the sum of the above risk compensation for inequity aversion and the risk compensation for asymmetric information.

$$
A C^{* *}=\Delta W^{F L^{* *}}+\Delta W^{R C^{* *}}
$$

Integrating the above analysis, it is clear that the agency cost increases with the intensity of inequity aversion within an upper limit defined by (40). By the egalitarian joint contract, even agents with inequity aversion don't suffer any inequity disutility, and the principal only need pay the fixed and hereby limited risk compensation for inequity aversion. However, by the relative joint contract, agents with inequity aversion suffer inequity disutility in face of unfair allocation, and the principal has to pay inequity rent, besides the risk compensation for inequity aversion. Whether the egalitarian joint contract or the relative joint contract is optimal depends on their respective agency costs. The one with lower agency costs is optimal. In case of relatively weak inequity aversion, agency cost of the relative joint contract is less and, therefore, it is the optimal, while in case of strong, even very strong inequity aversion, agency cost of the egali- 
tarian joint contract is smaller and, hence, it is the optimal.

\section{A Numerical Example}

In order to explain the above theoretical analysis clearly and fix ideas easily, the following offers a numerical example. The agent can achieve high output $x^{H}$ with probability of $p_{H}=0.8$ if he takes high effort $e_{H}$, while with probability of $p_{L}=0$ if he takes low effort $e_{L}$. Low effort $e_{L}$ costs 0 , while high effort $e_{H}$ costs $c=10$, privately to him. Further, denote $u(w)=\sqrt{w}$ with the reverse function $w=u^{2}$, by which $w_{a b}=\left(w_{h h}\right.$, $\left.w_{h l}, w_{l h}, w_{l l}\right)$ can be transformed as $u_{a b}=\left(u_{h h}, u_{h l}, u_{l h}, u_{l l}\right)$.

\subsection{Benchmark: Pure Self-Interest}

In the case of pure self-interest, $\alpha=\beta=0$. Therefore, [P3] is simplified as

[P5]

$$
\begin{aligned}
& \min _{u_{h h}, u_{h l}, u_{l h}, u_{l l}} 0.64 u_{h h}^{2} \\
& +0.16 u_{h l}^{2}+0.16 u_{l h}^{2}+0.04 u_{l l}^{2} \\
& \text { s.t. }\left\{\begin{array}{c}
(P C) 0.64 u_{h h}+0.16 u_{h l} \\
+0.16 u_{l h}+0.04 u_{l l} \geq 10 \\
(I C) 0.8 u_{h h}+0.2 u_{h l} \\
-0.8 u_{l h}-0.2 u_{l l} \geq 12.5
\end{array}\right.
\end{aligned}
$$

It is easy to find that the solution is $u_{a b}(0,0)=(12.5$, $12.5,0,0)$, and hereby the optimal contract is $w_{a b}(0$, $0)=(156.25,156.25,0,0)$, which is surely an independent contract.

On one side, the expected payment to each agent is

$$
E W_{r}(0,0)=0.8 \times 156.25+0.2 \times 0=125
$$

On the other side, the expected utility of each agent, excluding the cost of effort, is equivalent to $E U(0,0)=0.8 \times 12.5+0.2 \times 0=10$. If the principal can observe the efforts, he only has to pay certain as

$$
W^{C E}(0,0)=(E U(0,0))^{2}=10^{2}=100
$$

So, the risk compensation for asymmetric information, also the agency cost, can be denoted as

$$
\begin{aligned}
A C(0,0)= & \Delta W^{R C}(0,0)=E W_{r}(0,0) \\
& -W^{C E}(0,0)=125-100=25
\end{aligned}
$$

\subsection{Common Case: Average Inequity Aversion}

The average inequity aversion is denoted as $\alpha=0.8$ and $\beta=0.3$ [7]. Then, [P3] is simplified as
[P6]

$$
\begin{aligned}
& \min _{u_{h h}, u_{l l}, u_{l h}, u_{l l}} 0.64 u_{h h}^{2}+0.16 u_{h l}^{2} \\
& +0.16 u_{l h}^{2}+0.04 u_{l l}^{2} \\
& \text { s.t. }\left\{\begin{array}{c}
(P C) 0.64 u_{h h}-0.016 u_{h l} \\
+0.336 u_{l h}+0.04 u_{l l} \geq 10 \\
(I C) 0.8 u_{h h}+0.78 u_{h l} \\
-1.38 u_{l h}-0.2 u_{l l} \geq 12.5
\end{array}\right.
\end{aligned}
$$

The solution rounded to two decimal digits is $u_{a b}(0.8,0.3)=(13.65,9.50,4.21,0.07)$, and hereby the optimal contract with integer is $w_{a b}(0.8,0.3)=(186,90,18$, 0 ), which is surely a relative joint contract.

On one hand, the expected payment to each agent is

$$
\begin{aligned}
E W_{r}(0.8,0.3)= & 0.8 \times 0.8 \times 186+0.8 \times 0.2 \times 90 \\
& +0.2 \times 0.8 \times 18=136.32
\end{aligned}
$$

On the other hand, the utility of each agent in every case, excluding cost of effort, is denoted as

$$
\begin{aligned}
U_{a b}(0.8,0.3) & =\left\{\begin{array}{l}
U_{h h}=u_{h h} \\
U_{h l}=u_{h l}-\beta\left(u_{h l}-u_{l h}\right) \\
U_{l h}=u_{l h}-\alpha\left(u_{h l}-u_{l h}\right) \\
U_{l l}=u_{l l}
\end{array}\right. \\
& =\left\{\begin{array}{l}
13.65 \\
9.50-0.3 \times(9.5-4.21) \\
4.21-0.8 \times(9.5-4.21) \\
0.07
\end{array}\right. \\
& =\left\{\begin{array}{l}
13.65 \\
7.91 \\
-0.02 \\
0.07
\end{array}\right.
\end{aligned}
$$

For a pure self-interest agent, when endowed with the same utility as $U_{a b}(0.8,0.3)$ in every case, the expected payment he receives is

$$
\begin{aligned}
E W_{n}(0.8,0.3)= & 0.8 \times 0.8 \times 13.65^{2} \\
& +0.8 \times 0.2 \times 7.91^{2}-0.2 \times 0.8 \times 0.02^{2} \\
& +0.2 \times 0.2 \times 0.07^{2}=129.26
\end{aligned}
$$

where the negative payment is mapped to a negative utility. Therefore, the inequity rent is

$$
\begin{aligned}
W^{F R}(0.8,0.3) & =E W_{r}(0.8,0.3)-E W_{n}(0.8,0.3) \\
& =136.32-129.26=7.06
\end{aligned}
$$

While in order to endow him with the same utility as $\Delta U_{a b}(0.8,0.3)$ by the independent contract, the expected payment the principal has to make equals 


$$
\begin{aligned}
E W_{s}(0.8,0.3)= & 0.8 \times(0.8 \times 13.65+0.2 \times 7.91)^{2}- \\
& 0.2 \times(-0.8 \times 0.02+0.2 \times 0.07)^{2}=125
\end{aligned}
$$

where a negative payment is also mapped to the negative utility. Then, the risk compensation for inequity aversion is illustrated as

$$
\begin{gathered}
\Delta W^{F L}(0.8,0.3)=E W_{n}(0.8,0.3)-E W_{s}(0.8,0.3) \\
=129.26-125=4.26
\end{gathered}
$$

Then, the inequity aversion losses are

$$
\begin{aligned}
\Delta W^{F C}(0.8,0.3) & =\Delta W^{F R}(0.8,0.3)+\Delta W^{F L}(0.8,0.3) \\
& =7.06+4.26=11.32
\end{aligned}
$$

The expected utility of each agent, excluding effort cost, equals

$$
\begin{aligned}
E U(0.8,0.3)= & 0.8 \times 0.8 \times 13.65 \\
& +0.8 \times 0.2 \times 7.91-0.8 \times 0.2 \times 0.02 \\
& +0.2 \times 0.2 \times 0.07=10
\end{aligned}
$$

If the principal knows the efforts of all agents, he only has to pay a certain amount as

$$
W^{C E}(0.8,0.3)=(E U(0.8,0.3))^{2}=10^{2}=100 .
$$

consequently, the risk compensation for asymmetric information is

$$
\begin{aligned}
\Delta W^{R C}(0.8,0.3) & =E W_{s}(0.8,0.3)-W^{C E}(0.8,0.3) \\
& =125-100=25
\end{aligned}
$$

Summarily, the agency cost is

$$
\begin{aligned}
A C(0.8,0.3) & =\Delta W^{R C}(0.8,0.3)+\Delta W^{F C}(0.8,0.3) \\
& =25+11.32=36.32
\end{aligned}
$$

\subsection{Extreme Case: Infinite Inequity Aversion}

The above theoretical analysis has found that when inequity aversion is strong enough, the optimal contract is the egalitarian joint contract, by which payment to each independent agent is always equal, no matter what output each agent achieves. In order to illustrate it, the following four extreme cases, $(\alpha=10, \beta=0.4),(\alpha=100$, $\beta=0.4),(\alpha=300, \beta=0.4)$ and $(\alpha=500, \beta=0.4)$ are examined. The results in every case are given in Table 1.

From Table 1, the following conclusions can be drawn. (1) The optimal contract under weak inequity aversion is the relative joint contract, and trends towards the egalitarian joint contract as the intensity of inequity aversion increases. (2) Pure self-interest only requires risk compensation for asymmetric information, while inequity aversion results in inequity aversion losses, which increase with the intensity of inequity aversion within an upper limit. (3) Risk compensation for asymmetric information under pure self-interest is the same as that under inequity aversion because it arises from asymmet-

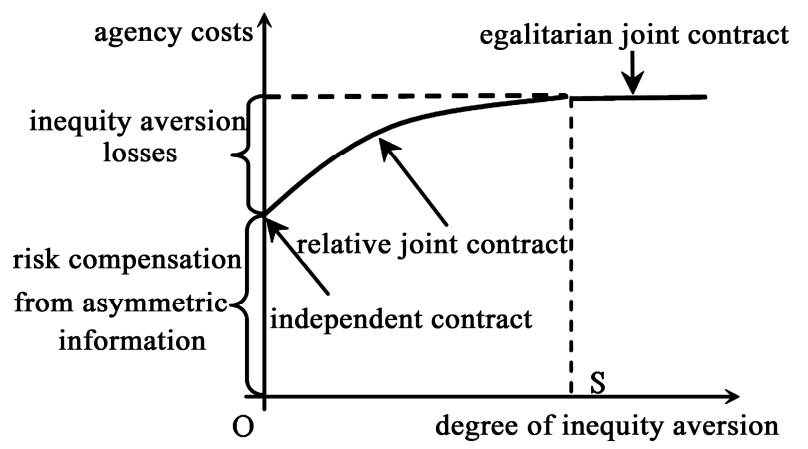

Figure 1. Relationships of inequity aversion, contract types and agency cost

ric information and is irrelative with the intensity inequity aversion. It is consistent with the former theoretical findings. A simple illustration of intuitive explanation is shown in Figure 1.

Under pure self-interest represented by point $O$, the optimal contract is the independent contract, and the agency cost includes only the risk compensation for asymmetric information. Under inequity aversion weaker than that of point $S$, the optimal contract is the relative joint contract, and the agency cost includes both the risk

Table 1. Computational results of optimal contract under different scenarios

\begin{tabular}{ccccccc}
\hline$(\alpha, \beta)$ & $u_{a b}$ & $w_{a b}$ & $\begin{array}{c}\text { Expected } \\
\text { payment }\end{array}$ & $\begin{array}{c}\text { Inequity aversion } \\
\text { losses }\end{array}$ & $\begin{array}{c}\text { Risk compensation for } \\
\text { asymmetric information }\end{array}$ & Agency costs \\
\hline$(0,0)$ & $(12.5,12.5,0,0)$ & $(156,156,0,0)$ & 125 & 0 & 25 & 25 \\
$(0.8 .0 .3)$ & $(13.86,9.50,4.21,0)$ & $(186,90,18,0)$ & 136.32 & 11.32 & 25 & 36.32 \\
$(10,0.4)$ & $(13.65,7.32,6.65,0)$ & $(192,54,44,0)$ & 138.56 & 13.56 & 25 & 38.56 \\
$(100,0.4)$ & $(13.65,6.98,6.92,0)$ & $(192,49,48,0)$ & 138.86 & 13.86 & 25 & 38.86 \\
$(300,0.4)$ & $(13.65,6.96,6.93,0)$ & $(192,48,48,0)$ & 138.88 & 13.88 & 25 & 38.88 \\
$(500,0.4)$ & $(13.65,6.95,6.94,0)$ & $(192,48,48,0)$ & 138.88 & 13.88 & 25 & 38.88 \\
\hline
\end{tabular}


compensation for asymmetric information and inequity aversion losses, which increase with intensity of inequity aversion. Under inequity aversion stronger than that of point $S$, the optimal contract is the egalitarian joint contract and the agency cost includes both risk compensation for asymmetric information and inequity aversion compensation, which doesn't increase with the intensity of inequity aversion any more.

\section{Concluding Remarks}

The above designs the optimal contract for multiple agents with inequity aversion and then analyzes the incentive efficiency losses resulting from inequity aversion. Incorporating inequity aversion into optimal contract design can improve our understanding of the real world incentives. If agents exhibit an aversion towards unfair allocations, the optimal contract is the joint contract by which payment to each independent agent depends on both his own output and others'. The optimal contract under relatively weak inequity aversion is the relative joint contract by which payment to each independent agent increases with both his own output and others', while that under strong, even very strong, inequity aversion is the egalitarian joint contract by which payment to each independent agent is always equal, no matter how many outputs an agent achieves independently. While the optimal contract designed in the standard contract theory balances insurance and incentives, the joint contract incorporating inequity aversion balances insurance, incentives and fairness. Therefore, the inequity aversion adds an additional incentive constraint because the principal has to pay inequity rent and risk compensation for inequity aversion by the joint contract besides risk compensation for asymmetric information by the independent contract investigated in the standard contract theory.

So, the inequity aversion results in incentive efficiency losses, which include inequity rent and risk compensation for inequity aversion, increase with the intensity of inequity aversion by the relative joint contract, while only include risk compensation for inequity aversion, is fixed and hereby is limited by the egalitarian joint contract. Therefore, in order to design the optimal contract for agents with inequity aversion, whether the relative joint contract or the egalitarian joint contract, the principal must screen and evaluate the intensity of inequity aversion. In this way, some new theoretical insights are obtained by incorporating inequity aversion into the standard frame of optimal contract design and hence real economic behaviors can be explained more properly.

However, there remain many open questions to be answered. Firstly, how to measure the intensity of inequity aversion? There are few economic literatures that discuss evaluation and screening of inequity aversion. Secondly, how to change the preferences of the agents on behalf of the principal? To be more frank, how can an employer change the intensity of inequity aversion of his employees? Although most activities of human resource management are targeted at shaping preferences of employees, there are few concrete feasible solutions available. Finally, what is the scope of the reference group? What is the time horizon? The right framing of social comparison is surely another important task. All these questions are worth exploring further.

\section{REFERENCES}

[1] C. F. Camerer and R. H. Thaler, "Ultimatums, dictators and manners,” Journal of Economic Perspective, Vol. 9, pp. 209-219, 1995.

[2] J. Berg, J. Dickhaut, and K. McCabe, "Trust, reciprocity and social history,” Games and Economic Behavior, Vol. 10, pp. 122-142, 1995.

[3] E. Fehr, G. Kirchsteiger, and A. Riedl, "Does fairness prevent marketing clearing,” Quarterly Journal of Economics, Vol. 11, pp. 437-460, 1993.

[4] E. Fehr and S. Gachter, "Cooperation and punishments in public goods experiments,” American Economic Review, Vol. 90, pp. 980-994, 2000.

[5] E. Fehr and A. Falk, "Psychological foundations of incentives,” European Economic Review, Vol. 46, pp. 687724, 2002.

[6] S. Gachter and E. Fehr, "Fairness in the labor market: A survey of experimental results," University of Zurich, Working Paper, 2001.

[7] E. Fehr and K. M. Schmidt, "A theory of fairness, competition and cooperation,” Quarterly Journal of Economics, Vol. 114, pp. 817-868, 1999.

[8] G. E. Bolton and A. Ockenfels, "ERC: A theory of equity, reciprocity and competition,” American Economic Review, Vol. 90, pp. 166-193, 2000.

[9] M. Rabin, "Incorporating fairness into game theory and economics,” American Economic Review, Vol. 83, pp. 1281-1302, 1993.

[10] M. Dufwenberg and G. Kirchsteiger, "A theory of sequential reciprocity,” Games and Economic Behavior, Vol. 47, pp. 269-298, 2004.

[11] F. Englmaier, "A survey on moral hazard, contracts and social preferences,” University of Munich, Working Paper, 2005.

[12] A. Falk, E. Fehr, and U. Fischbacher, "Testing theories of fairness-intentions matter," Games and Economic Behavior, Vol. 62, pp. 287-303, 2008. 
[13] F. Englmaier and A. Wambach, "Contracts and inequity aversion,” University of Munich, Working Paper, 2002.

[14] F. Englmaier and A. Wambach, "Optimal incentive contracts under inequity aversion,” IZA Discussion Paper, 2005.

[15] W. S. Neilson and J. Stowe, "Piece-rate contract for other-regarding workers,” Economic Inquiry, Forthcoming, 2009.

[16] R. Dur and A. Glazer, "Optimal incentive contracts when workers envy their bosses," Journal of Law, Economics, and Organization, Vol. 24, No. 1, pp. 120-137, 2008.

[17] R. Rob and P. Zemsky, "Social capital, corporate culture, and incentive intensity," RAND Journal of Economics, Vol. 32, pp. 243-257, 2002.

[18] S. Huck, D. Kubler, and J. Weibull, "Social norms and economic incentives in firms," IUI, Working Paper, 2003.

[19] D. Demougin and C. Fluet, "Output and wages with inequality averse agents," Canadian Journal of Economics, Vol. 39, No. 2, pp. 399-413, 2006.

[20] B. Barting and F. V. Siemens, "The intensity of incentives in firms and markets: Moral hazard with envious agents," University of Munich Discussion Paper, 2006.

[21] D. Demougin and C. Fluet, "Inequity aversion in tournament," Humboldt University Berlin, Working Paper, 2003.

[22] C. Grund and D. Sliwka, "Envy and compassion in tournament," Journal of Economics and Management Strategy, Vol. 14, pp. 187-207, 2005.

[23] P. Rey-Biel, "Inequity aversion and team incentives," Scandinavian Journal of Economics, Vol. 110, No. 2, pp. 297-320, June 2008.

[24] B. Barting and F. V. Siemens, "Efficiency in team production with inequity aversion agents," University of Munich, Working Paper, 2004.
[25] A. Mohnen, K. Pokorny, and D. Sliwka, "Transparency, inequity aversion, and the dynamics of peer pressure in teams: Theory and evidence,” Journal of Labor Economics, Vol. 26, No. 4, pp. 693-720, 2008.

[26] E. Kandel and E. P. Lazear, "Peer pressure and partnership,” Journal of Political Economy, Vol. 100, pp. 801 $-817,1992$.

[27] J. M. Barron and K. P. Gjerde, "Peer pressure in an agency relationship,” Journal of Labor Economics, Vol. 15, pp. 234-254, 1997.

[28] D. Masclet, "Peer pressure in work teams: The effects of inequity aversion,” University of Lyon Working Paper, 2002.

[29] H. Itoh, "Moral hazard and other-regarding preferences," Japanese Economic Review, Vol. 55, pp. 18-45, 2004.

[30] E. Fehr and K. M. Schmidt, "Theories of fairness and reciprocity: Evidence and economic applications,” Advances in Economics and Econometrics 8th World Congress, pp. 208-257, 2003.

[31] A. Falk and U. Fischbacher, "A theory of reciprocity," Games and Economic Behavior, Vol. 54, pp. 293-315, 2006.

[32] J. C. Cox, D. Friedman, and G. Steven, “A tractable model of reciprocity and fairness," Games and Economic Behavior, Vol. 59, No. 1, pp. 17-45, 2007.

[33] B. Holmstrom, “Moral hazard and observability,” Bell Journal of Economics, Vol. 10, pp. 74-91, 1979.

[34] B. Holmstrom, "Moral hazard in teams," Bell Journal of Economics, Vol. 13, pp. 324-340, 1982.

[35] E. P. Lazear and S. Rosen, "Rank-order tournament as optimum labor contracts,” Journal of Political Economy, Vol. 89, pp. 841-864, 1981.

[36] J. Yun, "On the efficiency of the rank-order contract under moral hazard and adverse selection,” Journal of Labor Economics, Vol. 15, pp. 466-494, 1997. 